\title{
Oncolytic adenovirus mediated Survivin knockdown by RNA interference suppresses human colorectal carcinoma growth in vitro and in vivo
} Wei Shen ${ }^{1,2}$, Chun-Yi Wang1,2, Xue-Hu Wang ${ }^{1,2}$ and Zhong-Xue Fu*1

\author{
Address: ${ }^{1}$ Department of General Surgery, The First Affiliated Hospital, Chongqing Medical University, Chongqing 400016, PR China and ${ }^{2}$ Key \\ laboratory of general surgery, The First Affiliated Hospital, Chongqing Medical University, Chongqing 400016, PR China \\ Email: Wei Shen - toby_shenwei@hotmail.com; Chun-Yi Wang -fzx_md@hotmail.com; Xue-Hu Wang - wangxuehu005@163.com; Zhong- \\ Xue Fu* - fzx_cqmu@hotmail.com \\ * Corresponding author
}

Published: 15 June 2009

Journal of Experimental \& Clinical Cancer Research 2009, 28:8I doi:I0.1 186/1756-9966-28-8I

This article is available from: http://www.jeccr.com/content/28/I/8I

(c) 2009 Shen et al; licensee BioMed Central Ltd.

This is an Open Access article distributed under the terms of the Creative Commons Attribution License (http://creativecommons.org/licenses/by/2.0), which permits unrestricted use, distribution, and reproduction in any medium, provided the original work is properly cited.
Received: 22 April 2009

Accepted: 15 June 2009

\begin{abstract}
Background: Colorectal cancer is a one of the most common alimentary malignancies. Survivin has been proved by many studies to be an ideal target for cancer gene therapy because of its strong anti-apoptotic effect. The reduction of Survivin expression by means of chemically synthesized small interfering RNA or small hairpin RNA expressed from plasmid and resulted growth inhibition of cancer cells had been proved by many studies including ours, but the transfection efficiency was not encouraging. So for the first time we constructed the Survivin shRNA into an oncolytic adenovirus, tested its effects on colorectal cancer cell lines and nude mice xenograft model.
\end{abstract}

Methods: In this study, we constructed an oncolytic adenovirus with a Survivin targeted small hairpin RNA and a reporter gene (ZD55-Sur-EGFP). The expression of Survivin mRNA and protein were analyzed by RT-PCR and western blot. The cell growth and apoptosis were tested by in vitro cytopathic assay, MTT assay and flow cytometry respectively. The effect of the constructed virus on xenograft model was evaluated by tumor volume and western blot analysis.

Results: ZD55-Sur-EGFP replicated in cancer cells specifically, reduced the expression of Survivin mRNA and protein expression effectively $(P<0.000 \mathrm{I})$, induced cancer cell apoptosis and inhibited SW480 cell growth both in vitro and in vivo significantly.

Conclusion: We conclude Survivin RNA interference combining with oncolytic adenovirus virotherapy to be a promising treatment for colorectal cancer.

\section{Background}

Colorectal cancer (CRC) is the second leading cause of cancer-related deaths in the US and the incidence is increasing rather rapidly in developing countries including China [1]. Traditional treatments for colorectal cancer such as surgical resection and chemotherapy do not increase the survival rate satisfactory enough. There are still 50\% patients died from tumor recurrence and metastasis. It is of great importance to find a new therapeutics against colorectal cancer.

Survivin, a member of the inhibitor of apoptosis protein (IAP) family, is expressed highly in most human tumors and fetal tissues, but is barely detectable in terminally dif- 
ferentiated cells [2]. The Survivin protein functions to inhibit caspase activation by interacting with caspases via baculovirus IAP repeat domains, therefore leading to negative regulation of apoptosis [3]. There was evidence by cDNA microarray that Survivin plays an important role in pathogenesis of colorectal cancer [4]. Several reports had successfully inhibited cancer cell growth by applying Survivin antagonists, antisense oligonuceotides or Survivin RNA interferences [5-7]. Thus Survivin is considered as an ideal target for colorectal cancer gene therapy [8].

ONYX-015, a well known E1B-55 kDa deleted adenovirus, has been used in clinical trials and achieved encouraging results. However, the therapeutic efficacy of ONYX015 is limited when it is used as a single agent $[9,10]$. So we constructed a new E1B-55 kDa deleted adenovirus with a cloning site for exogenous gene, which offered a possibility for treatment of carcinomas with both oncolytic adenovirus and specific gene targeted RNA interference. We showed that the construct, ZD55-Sur-EGFP, specifically replicated in colorectal cancer cells, induced apoptosis and attenuated cancer cell growth both in vitro and in nude mice. ZD55-Sur-EGFP may be a promising therapy for colorectal cancer.

\section{Methods \\ Construction of Survivin shRNA expression plasmid}

A pair of short hairpin RNA (shRNA) targeting Survivin [GeneBank accession NM_001168] which had been reported [6] was constructed. The sequence was a $19 \mathrm{nt}$ small interfering RNA: GGCTGGCTTCATCCACTGC (86104) with a ring sequence of 9 base pairs connecting the sense and antisense strands (TTCAAGAGA). The shRNA was constructed into pMD-18T plasmid (TaKaRa), namely pMD-18T-S. The sequence was not homologous with any human coding gene by BLAST analysis.

\section{Cell lines and cell culture}

Human colon adenocacinoma cell lines SW480, LoVo and intestinal epithelial cell (IEC) were obtained from Shanghai Cell Collection (Shanghai, China), HEK293 cells were purchased from Mircrobix Biosystems Ltd. (Canada). Cells were routinely cultured in Dulbecco's modified Eagle's media (Gibco) supplemented with 10\% (vol/vol) fetal bovine serum (Gibco) at $37^{\circ} \mathrm{C}$ in a humidified incubator containing $5 \% \mathrm{CO}_{2}$.

\section{Adenovirus construction}

We constructed an E1b-55 kDa deleted oncolytic adenovirus construction plasmid pZD55 as reported [11] and it was reserved in our laboratory, but we added a reporter gene expressing enhanced green fluorescence protein (EGFP) which allowed for tittering and measuring of infection efficiency in transfected cells. Briefly, pIRESEGFP (Clontech) was cut with EcoRI and XbaI to get the
EGFP fragment. Then the EGFP segment was ligated into pCA13 (Microbix Biosystems) and pZD55 respectively to form pCA13-EGFP and pZD55-EGFP. After that, the Survivin shRNA expression cassette was excised from pMD18T-Sur with XhoI and BamHI, first subcloned into pCA13-EGFP to form pCA13-Sur-EGFP. Then the expression cassette containing the Survivin shRNA controlled by the human CMV promoter and reporter gene EGFP were cut with Bgl II and subcloned into pZD55 to construct pZD55-Sur-EGFP. Oncolytic adenoviruses ZD55-SurEGFP, ZD55-EGFP, replication deficiency adenovirus ADSur-EGFP, AD-EGFP were generated by homologous recombination between pZD55-Sur-EGFP, pZD55-EGFP, pCA13-Sur-EGFP, pCA13-EGFP and the adenovirus packaging plasmid pBHGE3 (Microbix Biosystems) respectively. Viruses were purified by ultracentrifugation with cesium chloride. The titers were determined by cytopathic effect (CPE) on HEK293 cells in a 96-well plate by a fluorescence microscope.

\section{Detection of adenoviruses in cells}

SW480 and LoVo cells as well as intestinal epithelial cells (IEC) were plated at $10^{5}$ cells per $6 \mathrm{~cm}$ dish and infected with ZD55-Sur-EGFP or AD-Sur-EGFP for $48 \mathrm{~h}$ and $72 \mathrm{~h}$. The expression of enhanced green fluorescent protein (EGFP) was accessed by a Zeiss fluorescence microscope coupled with a digital camera photo apparatus.

\section{$R T-P C R$ analysis}

Total RNA from transfected cells was isolated using TRIzol (Invitrogen) as recommended by the manufacturer. RTPCR was used for the analysis of Survivin mRNA with GAPDH as an internal control. Primers for Survivin were as follow: forward primer 5'-GAC CAC CGC ATC TCT ACA TTC-3', reverse primer 5'-GTT CTT GGC TCT TTC TCT GTCC-3'. The GAPDH primers were forward 5'-ACC ACA GTC CAT GCC ATC AC-3' and reverse 5'-TCC ACC ACC CTG TTG CTG TA-3'. Reactions were performed in accordance with the standard protocol. PCR was performed by initial denaturation at $94^{\circ} \mathrm{C}$ for $5 \mathrm{~min}$ followed by 35 cycles of $30 \mathrm{~s}$ at $94^{\circ} \mathrm{C}, 30 \mathrm{~s}$ at $58^{\circ} \mathrm{C}$ and $60 \mathrm{~s}$ at $72^{\circ} \mathrm{C}$. The products were separated by electrophoresis in $2 \%$ agarose and visualized with ethidium bromide. Experiments were performed in triplicate.

\section{Western blot analysis}

Cells were transfected with adenoviruses and incubated for $48 \mathrm{~h}$. After that they were harvested and the protein extracts were separated via sodium dodecyl sulfate-polyacdene gel electrophoresis and transferred onto nitrocellulose membranes. The membranes were then blocked with rabbit anti-Survivin, Ad2 E1A, $\beta$-actin (Santa Cruz), XIAP (Sigma) and caspase-3 (Beyotime, China) primary polyclonal antibodies respectively at $4{ }^{\circ} \mathrm{C}$ overnight. After washing with PBS containing 0.05\% Tween 20 the mem- 
branes were incubated with secondary antibody (goat anti-rabbit, Santa Cruz) for $2 \mathrm{~h}$. They were visualized by chemiluminescence system according to manufacturer's instruction.

\section{In vitro cytopathic assay}

Cells were grown subconfluently and infected with adenoviruses with indicated MOIs. 5 days later, the medium was removed and the cells were washed with PBS twice, exposed to Coomassie brilliant blue and then washed with distilled water. The result was documented as photographs.

\section{MTT cell viability assay}

To quantify the cytopathic effect, MTT assay was performed. Cells were seeded in 96-well plates for $24 \mathrm{~h}$ at $1 \times$ $10^{4}$ per well. After 1 to 5 days of various viruses infection, $15 \mu \mathrm{l}$ MTT ( $5 \mathrm{mg} / \mathrm{ml}$ in PBS) was added to each well for 4 $\mathrm{h}$ incubation at $37^{\circ} \mathrm{C}$ followed by the addition of $150 \mu \mathrm{l}$ DMSO. Absorbance at $570 \mathrm{~nm}$ was measured for cell viability in each well.

\section{Flow cytometry evaluation}

Apoptosis of cells infected with adenoviruses at MOI of 5 was determined by flow cytometry (FCM) using Annexin V: PE Apoptosis Detection Kit I (BD Biosciences, USA) according to manufacturer's instruction. Briefly, Cells were washed twice with cold PBS and resuspended in binding buffer at a concentration of $1 \times 10^{5} \mathrm{cells} / \mathrm{ml}$. Then they were incubated with $5 \mu \mathrm{l}$ of PE Annexin V and $5 \mu \mathrm{l}$ of 7-AAD for $15 \mathrm{~min}$ at room temperature in the dark. At last, $400 \mu \mathrm{l}$ of binding buffer was added and cells were analyzed by flow cytometry.

\section{Animal studies}

Five-week-old, female BALBC/C nude mice were obtained from the Laboratory Animal Center of Chongqing Medical University. They were maintained in the specific pathogen free unit under isothermal conditions. All experimental procedures were carried out in accordance with the National Institute of Health Guide for the Care and Use of Laboratory Animals.

$5 \times 10^{6}$ SW480 cells suspended in $0.1 \mathrm{ml}$ serum free medium were implanted subcutaneously into the flank of nude mice. When tumors size reached about $100 \mathrm{~mm}^{3}$, mice were randomly divided into 5 groups with 6 mice in each group. ZD55-Sur-EGFP, ZD55-EGFP, AD-Sur-EGFP and AD-EGFP were injected through the tail vein with $5 \times$ $10^{8}$ PFU adenoviruses suspended in $100 \mu \mathrm{l}$ PBS or $100 \mu \mathrm{l}$ PBS alone for 3 days. Tumors were monitored by measuring tumor volume with a caliper. The volume was calculated by the formula: $\mathrm{V}\left(\mathrm{mm}^{3}\right)=$ length $\times$ width $^{2} / 2$. After 60 days experiment, the tumors were harvested for western blot analysis.

\section{Survivin protein expression in xenograft tumor}

Snap-frozen tumor samples were homogenized mechanically in a buffer ( $150 \mathrm{mM}$ sodium chloride, $0.1 \mathrm{M}$ Tris $(\mathrm{pH}$ 8), $1 \%$ Tween-20, $50 \mathrm{mM}$ diethyldithiocarbamic acid, 1 mM EDTA pH 8) containing protease inhibitors, before sonication and centrifugation at $4^{\circ} \mathrm{C}$ for $3 \mathrm{~min}$. The following steps were the same as above mentioned in the western blot analysis part.

\section{Statistical analysis}

All data were displayed as Mean $\pm S O D$, analyzed via analysis of variance and Student $t$ test, and processed by the statistical software SPSS 13.0. Statistical significance was assumed when $\mathrm{p}<0.05$.

\section{Results}

\section{Adenovirus construction and identification}

The recombinant adenoviral vector plasmid pZD55 had been constructed and reserved in our laboratory. Recombinant oncolytic adenovirus ZD55-Sur-EGFP was constructed by homologous recombination between pZD55Sur-EGFP and the packaging plasmid pBHGE3. The schematic picture shows the recombinant ZD55-Sur-EGFP (Shown in Fig 1). The result was confirmed by restrictive enzyme digestion assay and sequence assay. E1A expression was also examined by immunoblot with SW480 and LoVo cells infected with various adenoviruses, shown in Fig 2. Results showed cells transfected with oncolytic viruses expressed E1A protein.

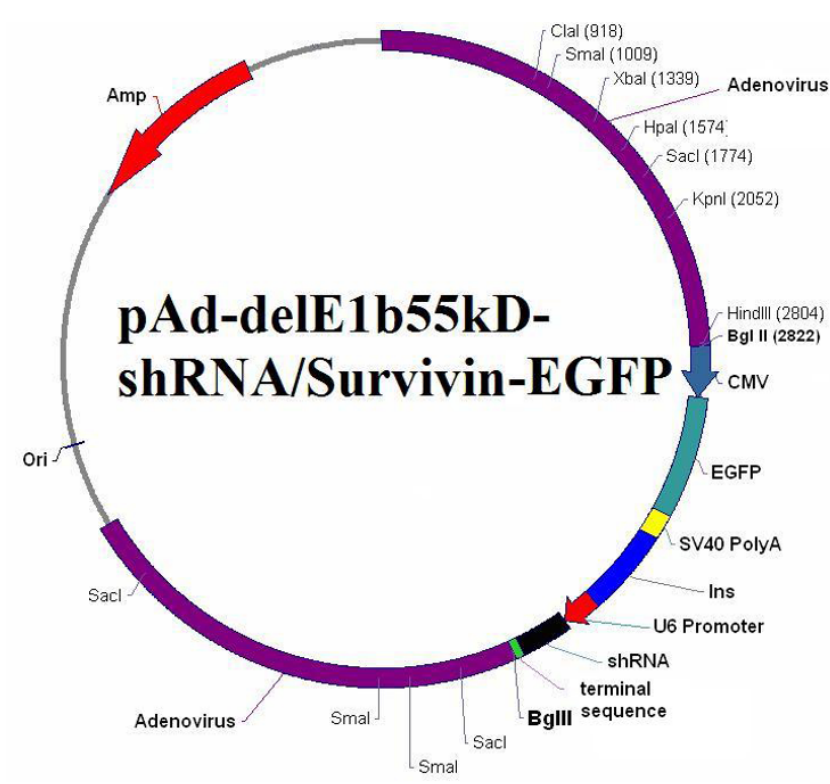

Figure I

The schematic presentation of ZD55-Sur-EGFP. The EIB-55KD gene was replaced by Survivin-shRNA sequence expression cassette and EGFP. 
SW480

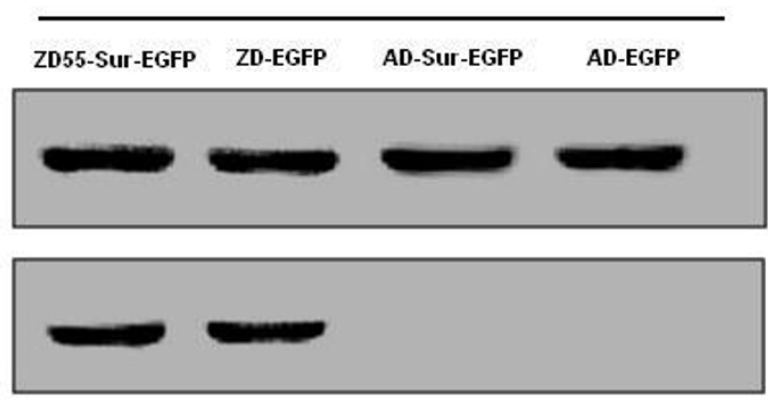

\section{LoVo}

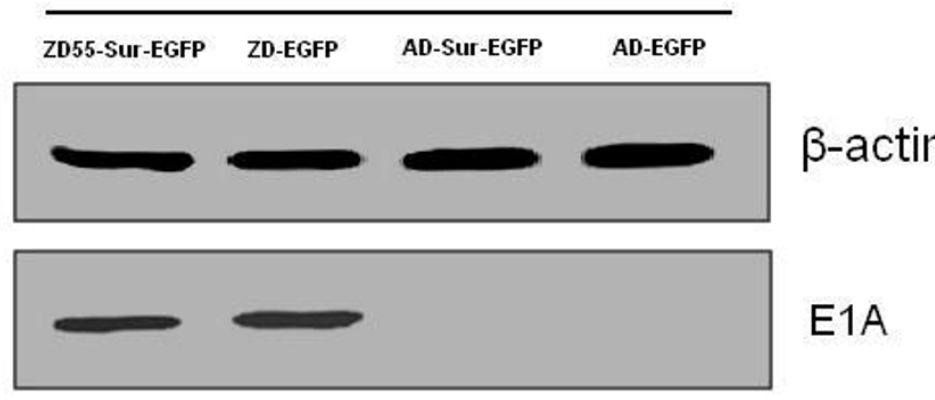

Figure 2

EIA expression in SW480 and LoVo cells infected with ZD55-Sur-EGFP, ZD55-EGFP, AD-Sur-EGFP and ADEGFP by immunoblot. AD-Sur-EGFP and AD-EGFP were EIA deleted viruses, the EIA protein was absent in this analysis.

\section{Reporter gene assay in vitro}

As shown in Fig 3a, the ZD55-Sur-EGFP demonstrated a high specificity to cancer cells. After $48 \mathrm{~h}$, stronger green fluorescence was observed in SW480 and LoVo cells infected with ZD55-Sur-EGFP than with AD-Sur-EGFP at MOI of 5. On the contrary, ZD55-Sur-EGFP showed much lower affinity to normal IEC cells compared with AD-SurEGFP. After $72 \mathrm{~h}$, the cancer cells infected with ZD55-SurEGFP became lysed but there was little change in the morphology of AD-Sur-EGFP infected cells.

\section{Inhibition of Survivin gene expression}

RT-PCR was performed $48 \mathrm{~h}$ after infection at MOI of 10 . Both ZD55-Sur-EGFP and AD-Sur-EGFP suppressed the expression of Survivin mRNA in SW480 and LoVo cells significantly, whereas ZD55-EGFP and Ad-EGFP showed little inhibition on Survivin mRNA. The Survivin protein expression analyzed by western blot was consistent with results from RT-PCR. The gels were analyzed by ImageMaster Total Lab software. Results showed ZD55-SurEGFP and AD-Sur-EGFP significantly down regulated the expression of Survivin protein but ZD55-EGFP and ADEGFP had little effect on Survivin expression. Importantly, infection of neither ZD55-Sur-EGFP nor AD-Sur-EGFP affected the expression of another anti-apoptotic protein XIAP. (Fig 4)

\section{Inhibition on in vitro growth and viability}

To detect the specific cytopathic effect of ZD55-Sur-EGFP in tumor cells, SW480, LoVo, as well as IEC cells, were infected with various adenoviruses at indicated MOIs. As shown in Fig 5. Marked cytopathic effect was observed in both tumor cell lines infected with ZD55-Sur-EGFP compared with ZD55-EGFP, AD-Sur-EGFP and AD-EGFP infected cells even at low MOIs. And ZD55-Sur-EGFP caused limited cell death in normal cell line IEC.
MTT cell viability assay demonstrated that SW480 and LoVo cells infected with ZD55-Sur-EGFP showed a significantly stronger CPE in a time-dependent manner. ZD55Sur-EGFP could kill colorectal cancer cells more powerfully compared with other groups (Fig 6).

\section{Apoptosis induced by adenoviruses}

As shown in Fig 7, the transfection of oncolytic adenoviruse with Survivin shRNA remarkably increased apoptotic populations in SW480 and LoVo cells by FCM analysis. The apoptotic rate in cancer cells transfected with ZD55Sur-EGFP (68.02\% and $63.79 \%$ ) was of great statistic significance compared with ZD55-EGFP (10.46\% and $13.38 \%)$, AD-Sur-EGFP (27.57\% and $31.09 \%$ ) and ADEGFP (6.14 and 6.74\%) groups

To confirm the apoptosis was mediated by caspase activation, we next examined the caspase- 3 activation by immunoblot analysis. In both SW480 and LoVo cells, the cleaved fragments of caspase- 3 increased along with the decrease of procaspase-3 in ZD55-Sur-EGFP and AD-SurEGFP infected groups, and the activation of caspase- 3 was more obvious in ZD55-Sur-EGFP group. Infections with ZD-EGFP and AD-EGFP did not affect the status of caspase-3 (Fig 8).

Effects of AD-Sur-EGFP on in vivo xenograft tumor model To further investigate the antitumor effect of oncolytic adenovirus mediated Survivin knock down on the in vivo CRC tumor growth. SW480 cells suspended in serum free medium were subcutaneously implanted into nude mice and various adenoviruses were injected via tail vein. 60 days later the mice were sacrificed and tumors were resected. The PBS treated group outgrowth other groups (2536.44 $\mathrm{mm}^{3}$ in volume). The mean volume of ZD55Sur-EGFP group was $108.80 \mathrm{~mm}^{3}$, which was much 
a

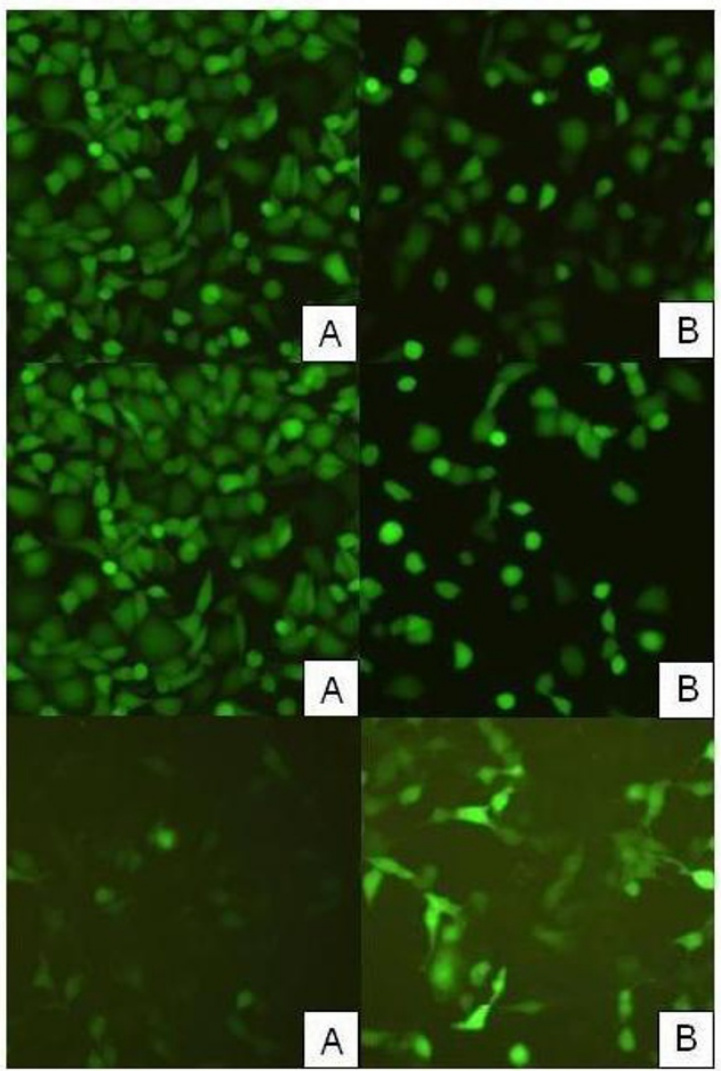

b

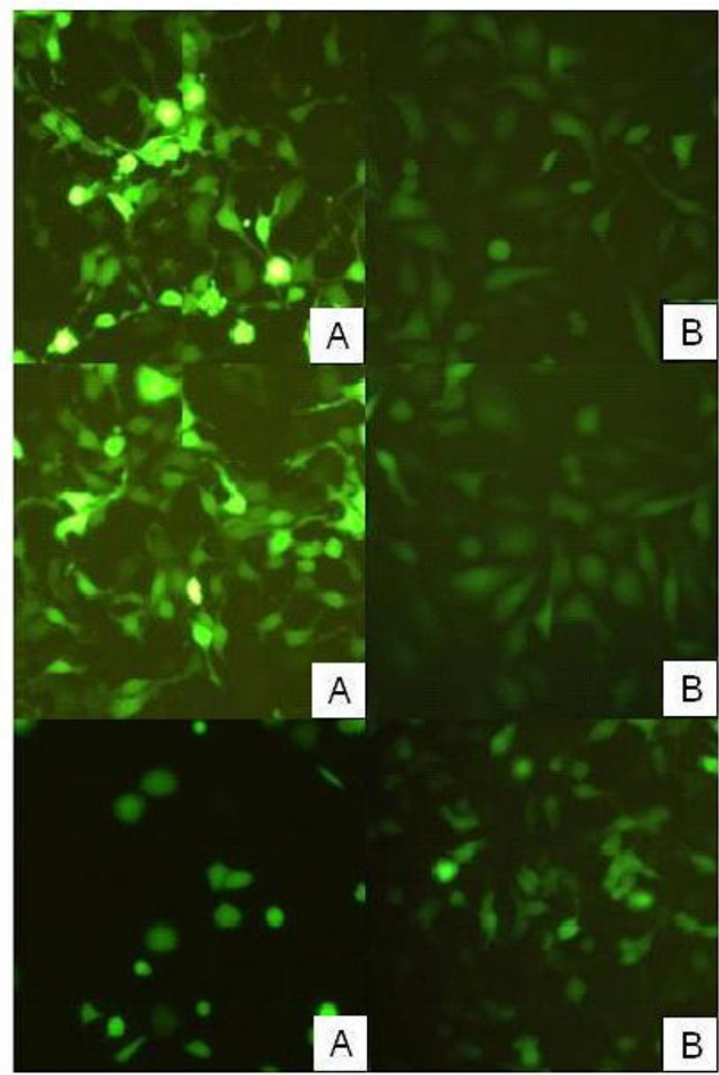

SW480

LoVo

IEC

\section{Figure 3}

SW480 and LoVo cells as well as IEC cells were plated at $10^{5}$ cells per $6 \mathrm{~cm}$ dishes and infected with ZD55-SurEGFP (A) or AD-Sur-EGFP (B) for $48 \mathrm{~h}$ (a) or $72 \mathrm{~h} \mathrm{(b)}$. Then the cells were observed through a fluorescence microscope. ZD55-Sur-EGFP showed much stronger affinity to SW480 cells than AD-Sur-EGFP, but it rarely replicated in normal cells IEC at $24 \mathrm{~h}$ post infection. After $72 \mathrm{~h}$, the cells infected with ZD55-Sur-EGFP became lysed but there was little change in the morphology of AD-Sur-EGFP infected cells. (Original magnification $\times 200$ ).

smaller than the ZD55-EGFP group $\left(863.56 \mathrm{~mm}^{3}\right)$, ADSur-EGFP group $\left(1224.97 \mathrm{~mm}^{3}\right)$, AD-EGFP group $\left(2278.21 \mathrm{~mm}^{3}\right)$ and PBS treated group (Fig 9a,b).

\section{Western blot analysis of Survivin in xenograft tumors}

To determine the effect of ZD55-Sur-EGFP on Survivin expression in vivo, we analyzed the Survivin protein in by western blot. As shown in Fig 9c, Survivin showed a marked reduction in ZD55-Sur-EGFP and AD-Sur-EGFP treated groups when compared with the PBS, AD-EGFP and ZD55-EGFP group. Furthermore, it is clearly that ZD55-Sur-EGFP suppressed Survivin expression more potent than AD-Sur-EGFP, and ZD55-EGFP, AD-EGFP and PBS had nearly no effect on Survivin expression.

\section{Discussion}

Colorectal carcinoma is the most frequent alimentary system malignancy, which accounts for $40 \%$ of the estimated new cancer cases of the digestive tract [12]. Although the incidence of CRC in developed countries is slowly decreasing, it is increasing rapidly in developing countries. Treatments such as surgical operation, adjuvant chemotherapy and neo adjuvant chemotherapy have achieved great progress [13], but the reported survival rate of CRC within five years is not yet encouraging. The mortality of CRC is mainly due to metastasis to distant organs, especially to liver, which accounts for one-third of the metastatic colorectal cancers [14-18]. It is urgent to establish a more effective therapeutics for CRC. 


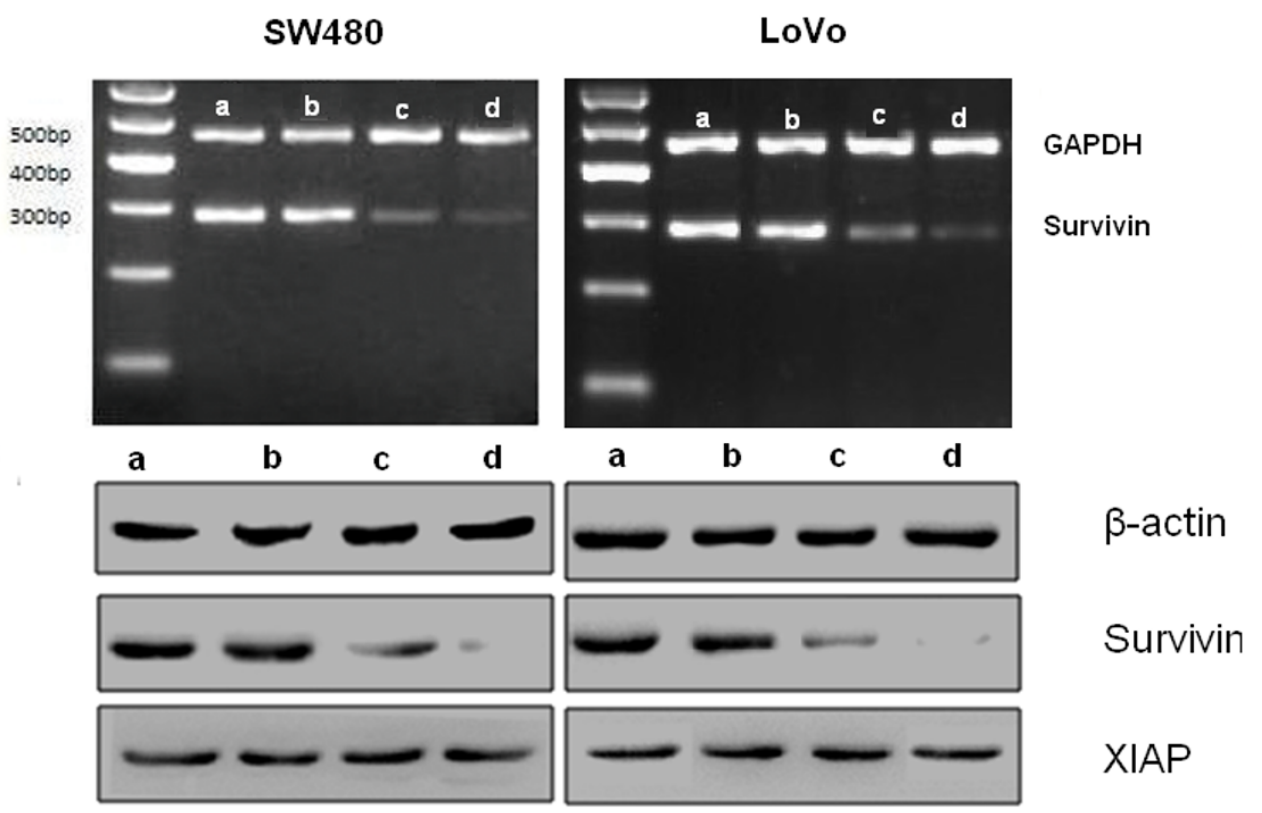

SW480

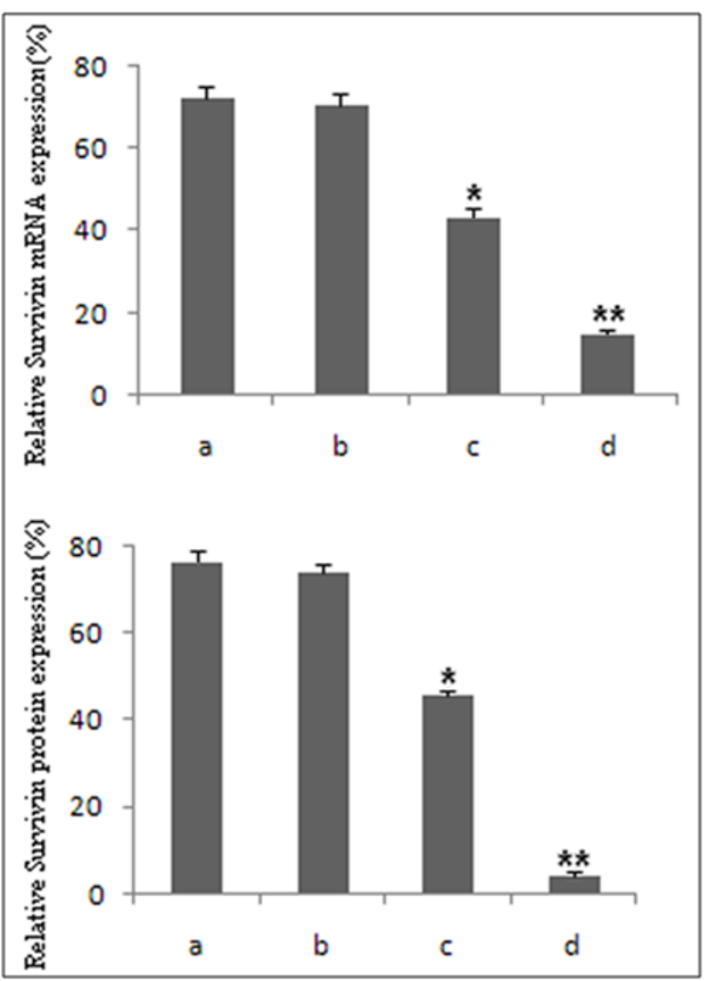

LoVo

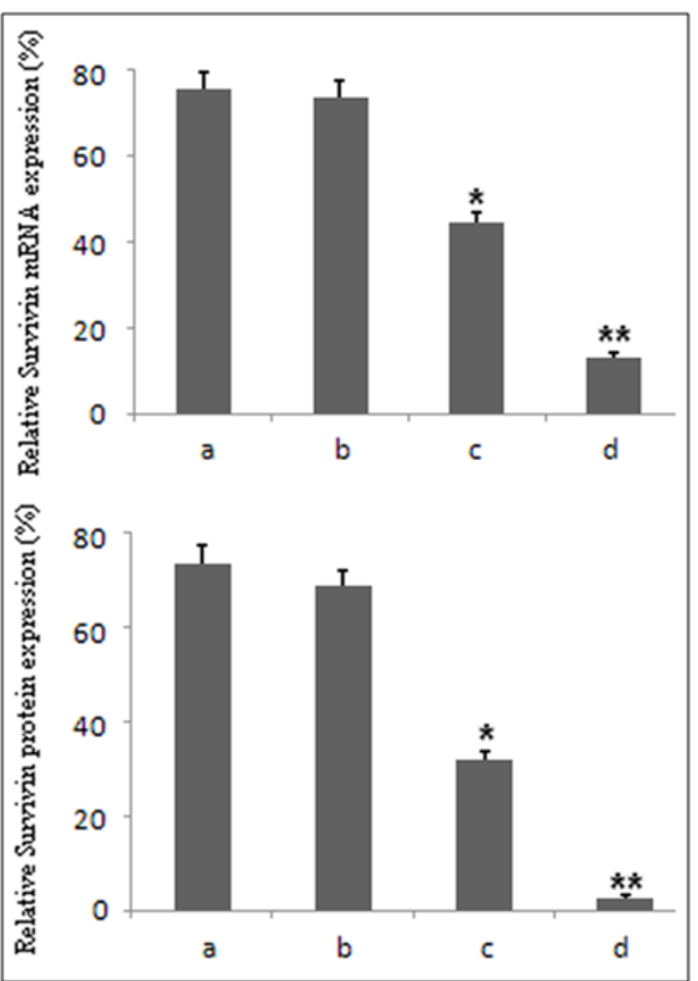

Figure 4

Inhibition of Survivin mRNA and protein expression in SW480 and LoVo cells. The cancer cells were treated with ZD55-Sur-EGFP, ZD55-EGFP, AD-Sur-EGFP and AD-EGFP respectively at MOI of 10. a: AD-EGFP group b: ZD55-EGFP group c: AD-Sur-EGFP group d: ZD55-Sur-EGFP group. (A) RT-PCR showed significant reduction of Survivin mRNA in ZD55-SurEGFP and AD55-Sur-EGFP treated cells. (B) Survivin protein levels in above mentioned groups were consistent with mRNA expression by Westen blot, and XIAP protein expression was not affected. $* * \mathrm{P}<0.000$ I, *P $<0.05$ 


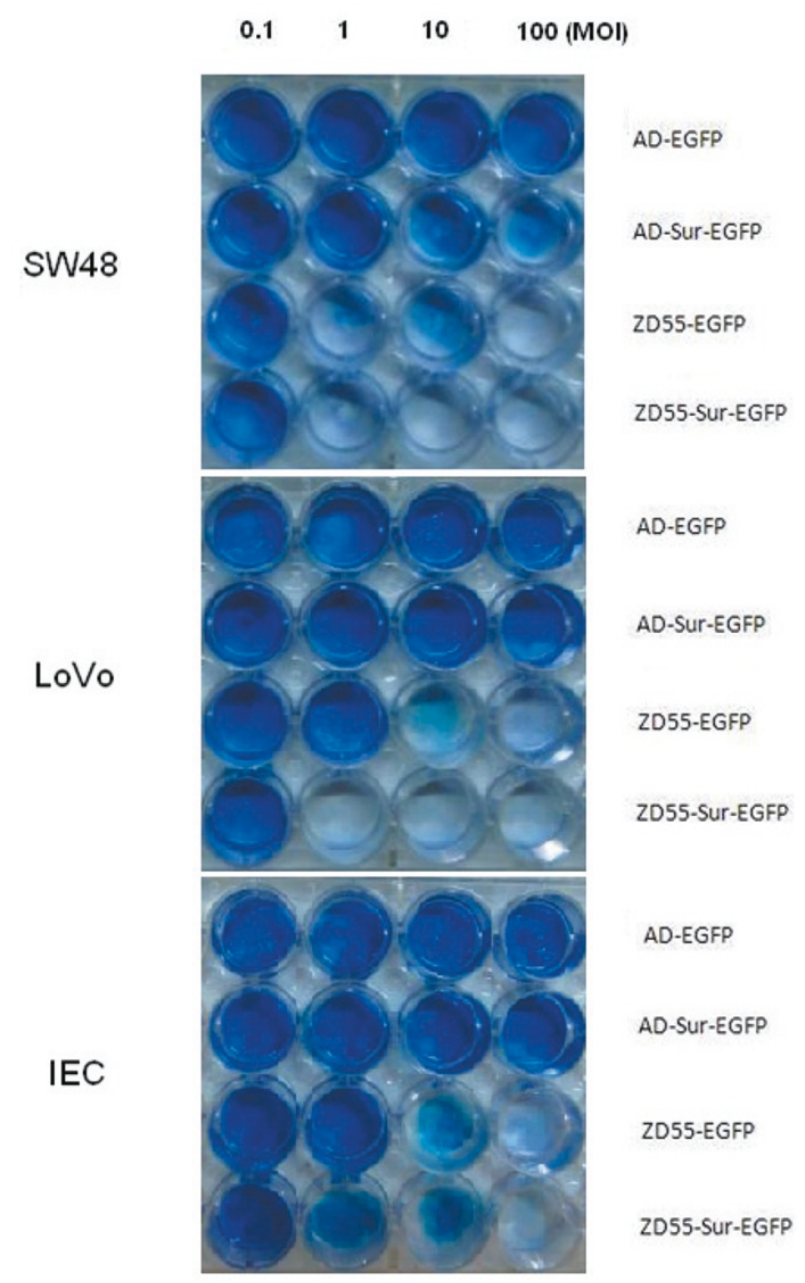

Figure 5

The impact of oncolytic adenovirus mediated RNAi against Survivin on SW480, LoVo and IEC cells. Cells were seeded in a 24 -well plate at $\mathrm{I} \times 10^{5}$ cells per well. Then they were infected with different adenoviruses at different MOls. At last, cells were stained with Coomassie brilliant blue.

RNA interference (RNAi) is a posttranscriptional gene silencing strategy first discovered in the nematode Caenorhabditis elegans [19]. Because of its high specifity and efficiency in down regulating gene expression, it has now become an excellent tool for exploring gene function. Many groups have worked on cancer gene silencing using RNAi in cell lines derived from different tissues, which lead to significant inhibition in cancer cell growth [2024]. Also there are some in vivo studies using RNA interference strategies which achieve similar results $[7,25]$. But the transfection efficiencies of traditional RNAi strategies are relatively low. In order to facilitate the application of RNAi in cancer gene therapies, improved methods for efficient introduction of small interfering RNA (siRNA) into target cells are needed.

Oncolytic adenovirus as an anticancer agent is a potent treatment in various malignancies [26]. The best known oncolytic adenovirus named ONYX-015 is an E1B-55 kDa deficiency virus, which has shown promising results in head-and-neck cancer treatment combining with chemotherapy $[27,28]$. Another oncolytic adenovirus, H101, similar to ONYX-015, was recently approved by the Chinese government to be used in combination with radiotherapy for head-and-neck cancers too [29]. Many works have been done to increase the efficacy of oncolytic adenovirus virotherapy. Oliver and his colleagues constructed an oncolytic adenovirus expressing Herpes Simplex Virusthymidine kinase which showed significant anti-neoplastic activity [30]. Another team from Taiwan used an E1Bdeleted adenovirus driven by the squamous cell carcinoma cell antigen 2 promoter for uterine cervical cancer therapy [26]. Sagawa and his colleagues reported a successful inhibition of hepatocellular carcinoma by combining conditionally replicable adenovirus driven by $\alpha$ fetoprotein enhancer/promoter (AFPep) with a replication-incompetent adenovirus carrying a p53 transgene also driven by AFPep [31]. But there is no report so far combining the oncolytic adenovirus with RNA interference in colorectal malignancy treatment.

ZD55 is a new E1B $55 \mathrm{kDa}$ deleted adenovirus vector which replicates specifically in tumor cells and lyses them. Researchers had successfully armed different therapeutic genes with ZD55 and showed significant antitumor effects [32]. To improve the efficiency and potency of Survivin shRNA, we constructed ZD55-Sur-EGFP, an E1B $55 \mathrm{kDa}$ deleted adenovirus carrying a Survivin targeted shRNA and a reporter gene.

In our study, we found the selectivity of ZD55-Sur-EGFP was much more obvious than that of AD-Sur-EGFP in colorectal cancer cell lines by reporter gene assay. We demonstrated that shRNA expressed from ZD55-SurEGFP significantly decreased Survivin expression of colorectal cancer cells as compared with AD-Sur-EGFP, but ZD55-EGFP and AD-EGFP had nearly no effect on Survivin expression. Moreover, the cytopathic effect of ZD55Sur-EGFP on the tumor cell lines was more apparent than that of ZD55-EGFP, AD-Sur-EGFP and AD-EGFP. These results suggest the selectivity of ZD55 could amplify the copies of shRNA in tumor cells and allow the viral infection to adjacent tumor cells, which further enhanced the RNAi potency. Furthermore, the oncolytic effect and Survivin RNAi synergistically suppressed tumor cell growth, leading to significant cell death. 

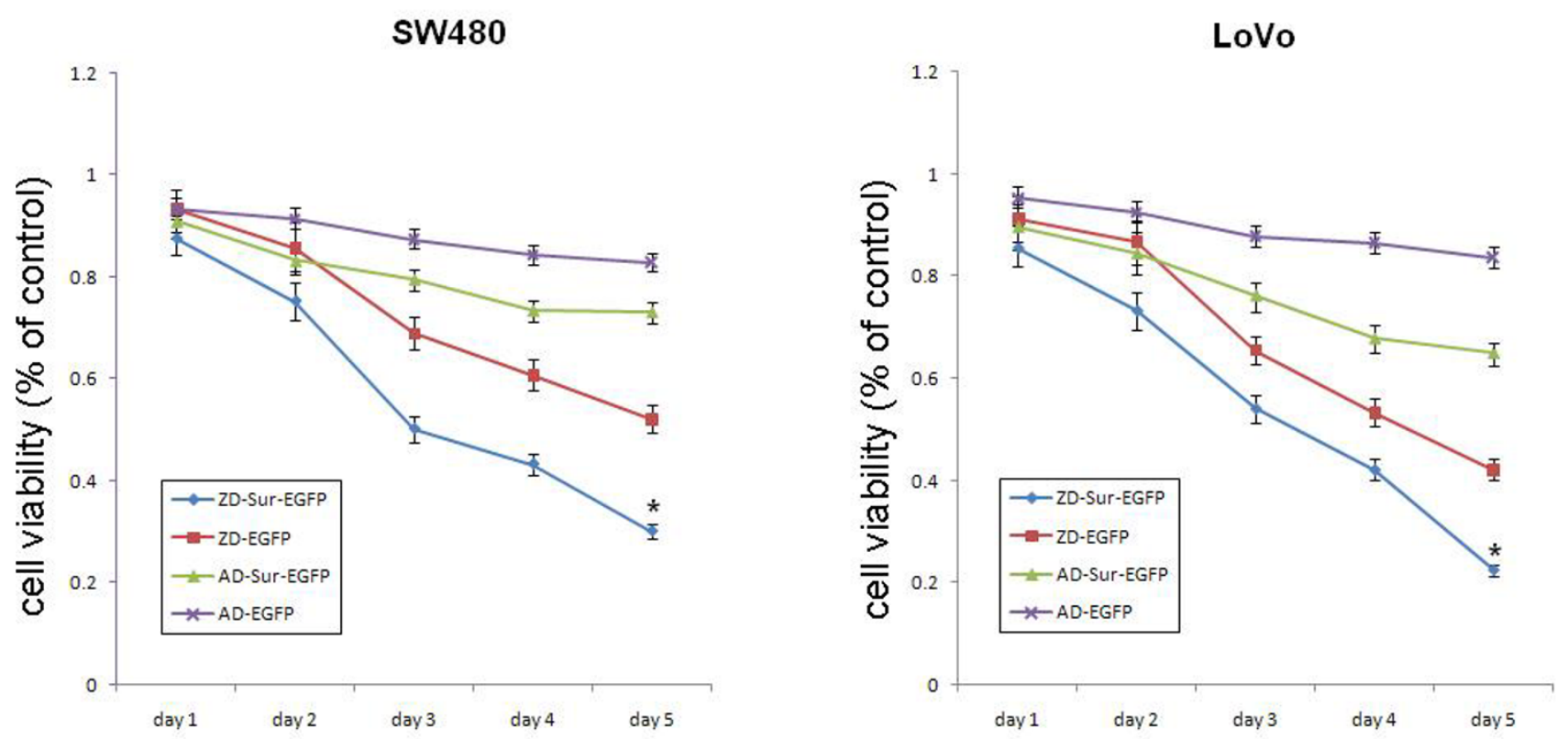

Figure 6

Cells were transfected with ZD55-Sur-EGFP, ZD55-EGFP ADS-Sur-EGFP and AD-EGFP respectively at MOI of 5. On I to 5 days post transfection, cells were subjected to MTT assay. This diagram shows the result of cell viability in each group. $* \mathrm{P}<0.000 \mathrm{I}$ vs other groups.
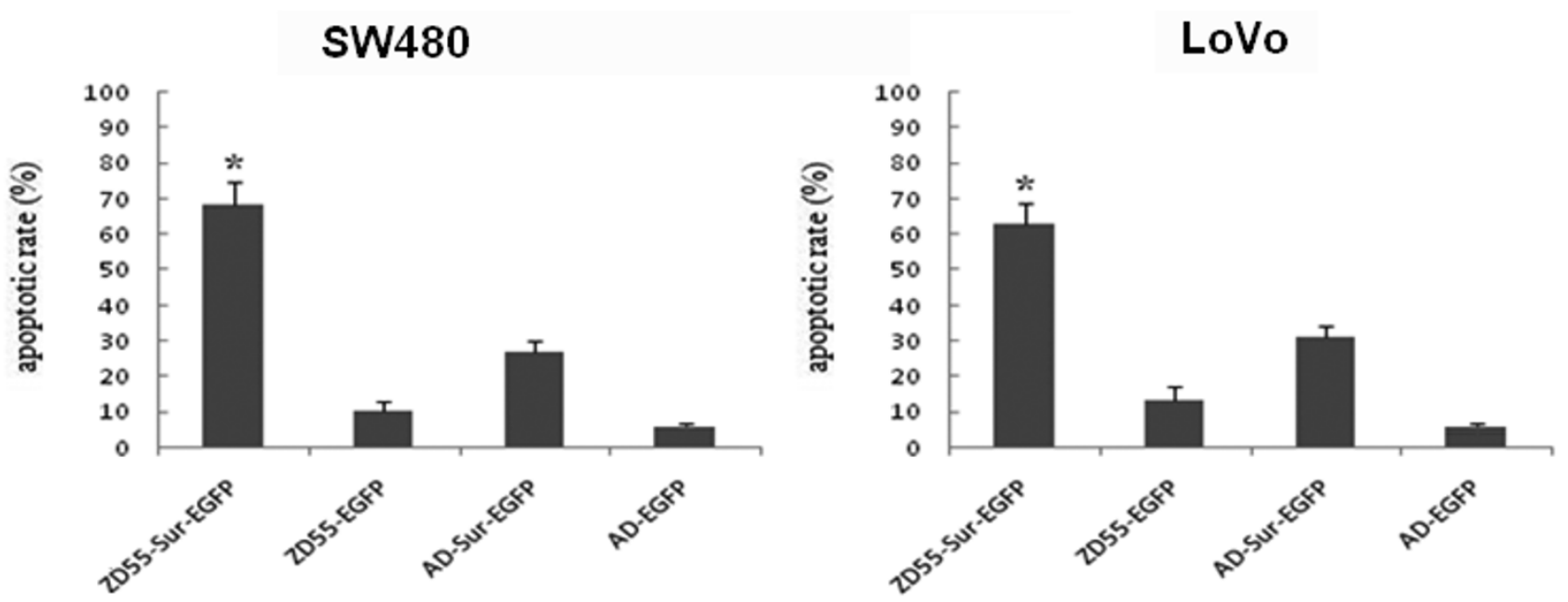

Figure 7

Cell apoptosis was detected by flow cytometry. The apoptotic rates of SW480 and LoVo cells infected with ZD55-SurEGFP were obviously higher $(68.02 \% \pm 6.88 \%$ and $63.79 \% \pm 6.06 \%$; $P<0.000 \mathrm{I})$ than that of ZD55-EGFP $($ I $0.46 \% \pm 2.31 \%$ and $13.38 \% \pm 3.05 \%)$, AD-Sur-EGFP $(27.57 \% \pm 2.49 \%$ and $31.09 \% \pm 2.68 \%)$ and AD-EGFP groups $(6.14 \% \pm 0.72 \%$ and $6.74 \% \pm$ $0.47 \%$ ). 


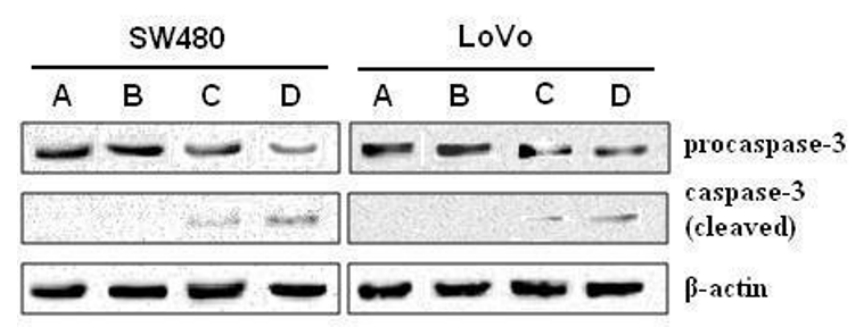

Figure 8

Effect of adenoviruses on caspase-3 activity in SW480 and LoVo cells. Western blot analysis was performed $48 \mathrm{~h}$ post infection. The activation of caspase-3 (demonstrated as increased expression of cleaved fragments of caspase-3) was more obvious in ZD455-Sur-EGFP group (D) than in AD-

Sur-EGFP group (C), whereas AD-EGFP (A) and ZD55-EGFP (B) did not actvivate caspase-3.
In our study, the data indicated ZD55-Sur-EGFP could induce much stronger apoptosis in both colorectal cancer cell lines than induced by ZD55-EGFP, AD-Sur-EGFP and AD-EGFP by activating caspases. Interestingly, we found infection of ZD55-EGFP had the potential to induce apoptosis, which was independent to Survivin regulation by RT-PCR and immunoblot analysis. A possible explanation is that some oncolytic virus structure proteins have an effect on the induction of tumor cell apoptosis and virus gene integration into the genome of cancer cells could lead to increased susceptibility to apoptosis [33].

In our present study, another interesting finding was that despite a remarkable induction of apoptosis as a consequence of the inhibition of Survivin after both infections of ZD55-Sur-EGFP and AD-Sur-EGFP, a significant decrease of cell viability was observed only after infection

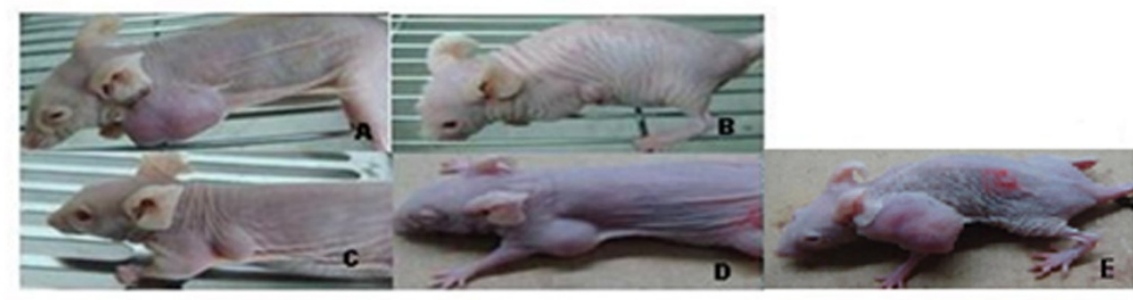

a

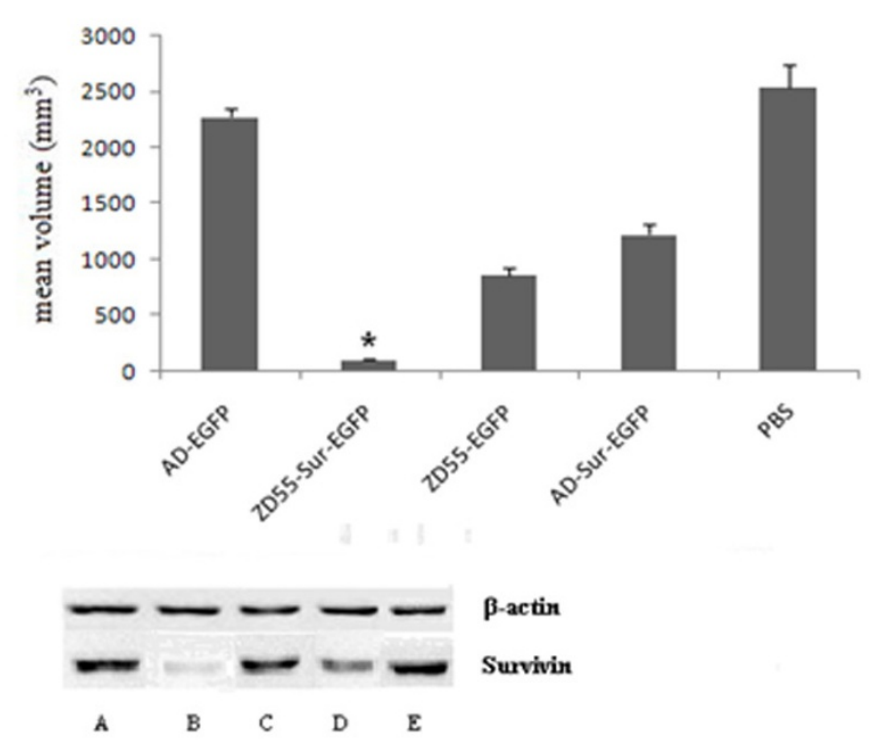

b

C

Figure 9

Antitumor effects of oncolytic virus mediated Survivin RNAi in nude mice xenograft tumor model. 4-week-old female BALBC/C nude mice were injected subcutaneously with SW480 cells and then with adenoviruses injected through the tail vein. After 60 days, the mice were sarcrificed and the tumors were harvested. A: AD-EGFP group B: ZD55-Sur-EGFP group C: ZD55-EGFP group D: AD-Sur-EGFP group E: PBS group (a) Representative tumor formations, 60 days after injection. (b) Tumor volume after 60 days of injection was quantitatively represented. Data were expressed as mean \pm SD. $* P<0.0$ I vs other groups (c) Western blotting of proteins from xenograft tumors. The result was consistent with that on cell level. 
with ZD55-Sur-EGFP in MTT assay. This phenomenon could be explained by the characteristics of both virus vectors. AD-Sur-EGFP is a replication deficient adenovirus which cannot replicate in tumor cells, initiating a limited time of Survivin down regulation and cell apoptosis; on the contrary, ZD55-Sur-EGFP can selectively replicate in those cells, delivering Survivin shRNA and then lyses the cells. This explanation is further confirmed by MTT assay: during the first two days, the cell viabilities in AD-SurEGFP group was lower than in ZD55-EGFP group, but after 2 days, the cell viability in ZD55-EGFP group became lower than AD-Sur-EGFP group because of the replication of oncolytic virus.

Previous study has shown that adenovirus based RNAi against Survivin led to significant inhibition of Survivin expression and tumor growth in vivo [7]. Our xenograft tumor model demonstrated that ZD55-Sur-EGFP has a more potent antitumor activity than that of ZD55-EGFP, AD-Sur-EGFP and AD-EGFP. Besides the direct anticancer effect of the oncolytic virus itself, the much more efficient Survivin shRNA delivering, gene silencing and induction of apoptosis contribute greatly to the potent antitumor activity.

\section{Conclusion}

In conclusion, the ZD55-Sur-EGFP has both the oncolytic ability and the capacity to deliver Survivin shRNA. This oncolytic adenovirus based Survivin RNA interference could efficiently reduce the cell growth, tumorigenicity and increase apoptosis of colorectal cancer cells, which offers a prospect of improvement in treatment of CRC, even a promising treatment for other human cancers.

\section{Competing interests}

The authors declare that they have no competing interests.

\section{Authors' contributions}

Wei Shen, Chun-Yi Wang and Zhong-Xue Fu designed the research; Wei Shen and Xue-Hu Wang participated in the cell research; Wei Shen carried out the animal study; all authors took part in result discussion and data analysis; Wei Shen wrote the paper. All authors read and approved the final manuscript.

\section{Acknowledgements}

This project is supported by grants from the National Natural Science Foundation of China (Nos. 30772547) and Doctoral Fund of Ministry of Education of China (No. 2006063 I013). We thank Key Laboratory of Opthalamology, Chongqing Medical University for equipments support.

\section{References}

I. Parkin DM, Bray F, Ferlay J, Pisani P: Global cancer statistics, 2002. CA Cancer J Clin 2005, 55:74- 108.

2. Sah NK, Khan Z, Khan GJ, Bisen PS: Structural, functional and therapeutic biology of Survivin. Cancer Lett. 2006, 244(2): |64-|7|.
3. Ambrosini G, Adida C, Altieri DC: A noble anti-apoptotic gene, Survivin, is expressed in cancer and lymphoma. Nat. Med 1997, 3:917-921.

4. Williams NS, Gaynor RB, Scoggin S, Verma U, Gokaslan T, Simmang C, Fleming J, Tavana D, Frenkel E, Becerra Cl: Identification and validation of genes involved in the pathogenesis of colorectal cancer using cDNA microarrays and RNA interference. Clin Cancer Res 2003, 9:931-46.

5. Yan H, Thomas J, Liu T, Raj D, London N, Tandeski T, Leachman SA, Lee RM, Grossman D: Induction of melanoma cell apoptosis and inhibition of tumor growth using a cell-permeable Survivin antagonist. Oncogene 2006, 25:6968-74.

6. Coma S, et al.: Use of siRNAs and antisense oligonucleotides against Survivin RNA to inhibit steps leading to tumor angiogenesis. Oligonucleotides 2004, I 4: |00-I35I.

7. Uchida $\mathrm{H}$, et al:: Adenovirus-mediated transfer of siRNA against survivin induced apoptosis and attenuated tumor cell growth in vitro and in vivo. Mol Ther 2004, 10:162-7I.

8. Zaffaroni N, Pennati M, Daidone MG: Survivin as a target for new anticancer interventions. J Cell Mol Med 2005, 9:360-72.

9. Khuri FR, et al.: A controlled trial of intratumoral ONYX-0I5, a selectively-replicating adenovirus, in combination with cisplatin and 5-fluorouracil in patients with recurrent head and neck cancer. Nat Med 2000, 6:879-85.

10. Heise C, Sampson-Johannes A, Williams A, McCormick F, Von Hoff DD, Kirn DH: ONYX-0I5, an EIB gene-attenuated adenovirus, causes tumor-specific cytolysis and antitumoral efficacy that can be augmented by standard chemotherapeutic agents. Nat Med 1997, 3:639-45.

II. Zhang ZL, Zou WG, Luo CX, Li BH, Wang JH, Sun LY, Qian QJ, Liu $X Y$ : An armed oncolytic adenovirus system, ZD55-gene, demonstrating potent antitumoral efficacy. Cell Res 2003, 13:481-9.

12. Jemal A, Siegel R, Ward E, Hao Y, Xu J, Murray T, Thun MJ: Cancer statistics, 2008. CA Cancer J Clin 2008, 58:7I-96.

13. Bar-Sela G, Haim N: Abnoba-viscum (mistletoe extract) in metastatic colorectal carcinoma resistant to 5-fluorouracil and leucovorin-based chemotherapy. Med Oncol 2004, 2 I:25I-4.

14. Bernhardson BM, Tishelman C, Rutqvist LE: Chemosensory changes experienced by patients undergoing cancer chemotherapy: a qualitative interview study. J Pain Symptom Manage 2007, 34:403-12.

15. Joosten J, Jager G, Oyen W, Wobbes T, Ruers T: Cryosurgery and radiofrequency ablation for unresectable colorectal liver metastases. Eur J Surg Oncol 2005, 3 I : I | 52-9.

16. Gravalos C, García-Sanchez L, Hernandez M, Holgado E, Alvarez N, García-Escobar I, Martínez J, Robles L: Surgical resection of a solitary pancreatic metastasis from colorectal cancer: a new step to a cure? Clin Colorectal Cancer 2008, 7:398-40I.

17. Renouf $D$, Kennecke H, Gill S: Trends in chemotherapy utilization for colorectal cancer. Clin Colorectal Cancer 2008, 7:386-9.

18. Pozzo C, Basso M, Cassano A, Quirino M, Schinzari G, Trigila N, Vellone M, Giuliante F, Nuzzo G, Barone C: Neoadjuvant treatment of unresectable liver disease with irinotecan and 5-fluorouracil plus folinic acid in colorectal cancer patients. Ann Oncol 2004, I 5:933-9.

19. Couzin J: Breakthrough of the year. Small RNAs make big splash. Science. 2002, 20(298):2296-2297.

20. Chen T, Deng C: Inhibitory effect of siRNA targeting survivin in gastric cancer MGC-803 cells. Int Immunopharmacol 2008, 8: $1006-11$.

21. Zhen HN, Li LW, Zhang W, Fei Z, Shi CH, Yang TT, Bai WT, Zhang $X$ : Short hairpin RNA targeting survivin inhibits growth and angiogenesis of glioma $\mathbf{2} 25$ I cells. Int J Oncol 2007, 3 I : I I I I-7.

22. Li QX, et al.: Survivin stable knockdown by siRNA inhibits tumor cell growth and angiogenesis in breast and cervical cancers. Cancer Biol Ther 2006, 5:860-6.

23. Sun BS, et al.: Lentiviral-mediated miRNA against osteopontin suppresses tumor growth and metastasis of human hepatocellular carcinoma. Hepatology 2008, 48: I834-42.

24. Charames GS, Bapat B: Cyclooxygenase-2 knockdown by RNA interference in colon cancer. Int J Oncol 2006, 28:543-9.

25. Wai PY, Mi Z, Guo H, Sarraf-Yazdi S, Gao C, Wei J, Marroquin CE, Clary B, Kuo PC: Osteopontin silencing by small interfering 
RNA suppresses in vitro and in vivo CT26 murine colon adenocarcinoma metastasis. Carcinogenesis 2005, 26:74I-5I.

26. Hsu KF, Wu CL, Huang SC, Hsieh JL, Huang YS, Chen YF, Shen MR, Chung WJ, Chou CY, Shiau AL: Conditionally replicating EIBdeleted adenovirus driven by the squamous cell carcinoma antigen 2 promoter for uterine cervical cancer therapy. Cancer Gene Ther 2008, 15:526-34.

27. Bischoff JR, et al.: An adenovirus mutant that replicates selectively in p53-deficient human tumor cells. Science 1996, 274:373-6.

28. Heise CC, Williams AM, Xue S, Propst M, Kirn DH: Intravenous administration of ONYX-OI 5, a selectively replicating adenovirus, induces antitumoral efficacy. Cancer Res 1999, 59:2623-8.

29. Liu TC, Kirn D: Gene therapy progress and prospects cancer: oncolytic viruses. Gene Ther 2008, I 5:877-84.

30. Wildner O, Blaese RM, Morris JC: Therapy of colon cancer with oncolytic adenovirus is enhanced by the addition of herpes simplex virus-thymidine kinase. Cancer Res 1999, I 5(59):410-3.

31. Sagawa T, et al:: Treatment of hepatocellular carcinoma by AdAFPep/rep, AdAFPep/p53, and 5-fluorouracil in mice. Hepatology 2008, 48:828-40.

32. Zheng JN, Pei DS, Mao LJ, Liu XY, Mei DD, Zhang BF, Shi Z, Wen RM, Sun $X Q$ : Inhibition of renal cancer cell growth in vitro and in vivo with oncolytic adenovirus armed short hairpin RNA targeting Ki-67 encoding mRNA. Cancer Gene Ther 2009, 16:20-32.

33. Wu YM, Zhang KJ, Yue XT, Wang YQ, Yang Y, Li GC, Li N, Wang YG: Enhancement of tumor cell death by combining cisplatin with an oncolytic adenovirus carring MDA-7/IL-24. Acta Pharmacol Sin 2009, 30:467-477.

Publish with Bio Med Central and every scientist can read your work free of charge

"BioMed Central will be the most significant development for disseminating the results of biomedical research in our lifetime. "

Sir Paul Nurse, Cancer Research UK

Your research papers will be:

- available free of charge to the entire biomedical community

- peer reviewed and published immediately upon acceptance

- cited in PubMed and archived on PubMed Central

- yours - you keep the copyright

Submit your manuscript here:

http://www.biomedcentral.com/info/publishing_adv.asp
BiolMedcentral 